\title{
The effects of socio-economic status on BMI, waist:hip ratio and waist circumference in a group of Iranian women
}

\author{
Mansour Shahraki ${ }^{1}$, Touran Shahraki ${ }^{2, *}$ and Hossein Ansari ${ }^{3}$ \\ 'Department of Nutrition, Faculty of Medicine, Zahedan University of Medical Sciences, Zahedan, Islamic \\ Republic of Iran: ${ }^{2}$ Department of Pediatrics, Faculty of Medicine, Zahedan University of Medical Sciences, \\ PO Box 98165-493, Zahedan, Islamic Republic of Iran: ${ }^{3}$ Department of Public Health, Faculty of Health, \\ Zahedan University of Medical Sciences, Zahedan, Islamic Republic of Iran
}

Submitted 20 March 2007: Accepted 13 September 2007: First published online 15 January 2008

\begin{abstract}
Objective: To assess the effects of socio-economic status (SES) on BMI, waist:hip ratio (WHR) and waist circumference (WC) in a group of Iranian women.

Methods: A cross-sectional study was conducted on 888 women in Sistan and Baluchestan Province. SES was measured using level of education. In addition, parity, marital status and physical activity were assessed. Standardized measurements were taken, BMI and WHR were calculated.

Results: Low education level was a strong determinant of overweight and obesity among Iranian women. After controlling for age, women with higher education level had significantly lower BMI, WC and parity. Multiple linear regression analysis found a significant negative association of BMI and WC with education level and a significant positive association of BMI and WC with parity. Significant factors associated with obesity by a logistic regression model were education level (OR for university graduates $v$. illiterate or low literacy levels: $1.00 \quad v .3 \cdot 70$; $P=0 \cdot 01$ ), living with spouse (OR for married $v$. single subjects: $1 \cdot 00 v \cdot 0 \cdot 15$; $P=0 \cdot 05$ ), parity (OR for more than five $v$. less than two pregnancies: $1 \cdot 00 v \cdot 0 \cdot 34$; $P=0.03$ ) and WC (OR for $<0.88 \mathrm{~cm} v$. $\geq 0.88 \mathrm{~cm}: 1 \cdot 00 v .11 \cdot 20 ; P=0 \cdot 001$ ).

Conclusion: The present study revealed that educational level, multiple pregnancies, marital status and lack of exercise are some possible explanations for the obesity among Sistan and Baluchestan women.
\end{abstract}

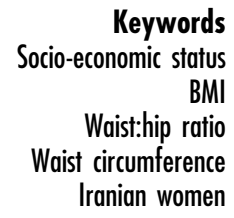

Socio-economic status (SES) is a complex issue characterized by income, education, occupation, marital status and residence status ${ }^{(1-3)}$. Although a positive energy balance over a prolonged period is essential for the development of obesity, it is crucial to understand how individual and socio-economic factors may lead to an energy imbalance. SES has been identified as an important factor associated with obesity, particularly in women, because SES influences an individual's access to resources, knowledge of nutrition and physical activity ${ }^{(4)}$.

Many studies have documented the higher rates of obesity and overweight among low-SES groups ${ }^{(5,6)}$. The relationship between SES and obesity may vary in industrialized and developing countries ${ }^{(7,8)}$. However, other factors, such as parity in women, have been positively associated with weight gain ${ }^{(9-11)}$.

The Islamic Republic of Iran has undergone increasing changes in the prevalence of obesity in recent dec$\operatorname{ades}^{(12-14)}$. The prevalence is reported to be $22-40 \%$ in urban regions and 16-26\% in rural regions of Tehran (Iran's capital city) ${ }^{(15)}$. One of the provinces in south-east Iran is Sistan and Baluchestan. In the past, as a result of tradition, some men in this region did not like outside employment and education for their wives. Today, this attitude has changed because of improving social thoughts. Also, higher education is now provided by many governmental and private universities and colleges. Therefore, the number of women who enter into higher education is increasing. This has caused educated women to pay more attention to their body shape than before. Moreover, the average number of children born to Sistan and Baluchestan women is still higher than in other regions of Iran ${ }^{(16)}$. In this regard, the aim of the present study was to determine the effects of educational level, parity, physical activity and marital status on BMI, waist:hip ratio (WHR) and waist circumference (WC) in a group of Iranian women. The present findings may be applied to target future interventions and research.

\section{Methods}

\section{Study subjects}

The present study considers cross-sectional data from Sistan and Baluchestan Province in Iran collected 
between August 2004 and September 2006. This province is located in south-east Iran and contains eight cities. Women who attended two health clinics in two locations in Zahedan were selected. These centres have subjects referred from different parts of Sistan and Baluchestan Province with low, middle and high socio-economic groups. The selected clinics belonged to the public sector, so the samples could be representative of women in this province. The subjects were 888 women all of whom were visited by a single nutritionist. Data collected for each subject included age, weight, height, waist and hip circumferences, marital status, level of education, reproductive history and physical activity. The subjects gave verbal consent for participation in this study.

\section{Antbropometric measurements}

BMI was calculated as weight in kilograms divided by the square of height in metres. Waist and hip circumferences were measured during the clinical visit with the subject standing relaxed and in underclothes only. WC was measured at the horizontal point between the costal margin and iliac crest that yielded the minimum measurement. Hip circumference was measured at the horizontal level around the buttocks that yielded the maximum measurement. Then WHR was calculated as the waist circumference divided by the hip circumference. All measurements were done by a trained staff and the instruments were calibrated regularly during the work.

\section{Inclusion and exclusion criteria}

All participants were originally from different parts of Sistan and Baluchestan Province and had lived there for at least 5 years previously. All subjects were more than 20 years old. The subjects had no metabolic illness, as judged by blood and urine analyses, and none were on a diet or medication. Pregnant women and those who were divorced, separated or widowed were excluded from the study. Based on WHO standards for BMI (underweight, BMI $<18.5 \mathrm{~kg} / \mathrm{m}^{2}$; normal weight, BMI $=18 \cdot 5-24.9 \mathrm{~kg} / \mathrm{m}^{2}$; overweight, $\mathrm{BMI}=25 \cdot 0-29 \cdot 9 \mathrm{~kg} / \mathrm{m}^{2}$; obese, $\mathrm{BMI} \geq 30 \cdot 0 \mathrm{~kg} /$ $\left.\mathrm{m}^{2}\right)^{(17)}$, women with BMI between $25 \cdot 0$ and $39 \cdot 9 \mathrm{~kg} / \mathrm{m}^{2}$ were included in the study. Also, Pakistani and Afghan immigrant women were excluded from the study (this province is located at the border with Pakistan and Afghanistan).

\section{Variables}

Most commonly used variables to measure SES are education, income and occupational status ${ }^{(1,2)}$. Of course, each of these parameters has its own strengths and limitations. Some researchers have used educational level as an indication of SES ${ }^{(18-20)}$. In the current study we used education level for the following reasons: (i) education is less affected by a subject's body weight, whereas her income might be affected; (ii) education is more comparable across time than income or occupation; and (iii) some subjects did not indicate their actual income.
On the basis of education, subjects were classified into three categories: illiterate or low literacy (no education or education completed at $<8$ years of schooling), intermediary and high school (education completed at between 8 and 12 years of schooling or subsequent non-university studies), and university graduates.

Physical exercise was defined as exercising for at least $20 \mathrm{~min}$ and outside professional activity (never, less than once a week, at least once a week). Parity was defined as the number of live births and stillbirths of each woman. Marital status comprised two groups: living single and married.

\section{Statistical analysis}

All statistical analyses were performed using the Statistical Package for the Social Sciences (SPSS/PC) statistical software package version 13 for Windows (SPSS Inc., Chicago, IL, USA). The results are presented as mean with standard deviation or proportion. Analyses of covariance were used to determine the relationship of BMI, WHR, WC and parity with educational level, controlling for age. We conducted multiple linear regression analyses and examined the relationship between BMI, WHR and WC as dependent variables and age, education and parity as independent variables. Logistic regression analyses were used to find the associations between obesity as binary dependent variable and educational level, parity, marital status and physical activity as independent variables. OR and 95\% CI were also estimated, and $P<0.05$ was considered to indicate significance.

\section{Results}

The mean age, BMI, WHR, WC, education level and parity of the participants were $33 \cdot 2$ (SD 9.6) years, 33.5 (SD 5.8) $\mathrm{kg} / \mathrm{m}^{2}, 0 \cdot 98$ (SD $\left.2 \cdot 20\right), 101 \cdot 2$ (SD $\left.14 \cdot 6\right) \mathrm{cm}, 11 \cdot 3(\mathrm{sD} 4 \cdot 0)$ years and $2 \cdot 8(\mathrm{SD} 2 \cdot 1)$, respectively. Of the women, 750 $(84 \cdot 5 \%)$ and $138(15 \cdot 5 \%)$ were married and single, respectively (Table 1$)$. In the present study, most subjects

Table 1 Sociodemographic characteristics and anthropometric measures of participants: Iranian women, Sistan and Baluchestan Province $(n 888)$

\begin{tabular}{|c|c|c|}
\hline Characteristic & Mean & SD \\
\hline Age (years) & $33 \cdot 2$ & $9 \cdot 6$ \\
\hline $\mathrm{BMI}\left(\mathrm{kg} / \mathrm{m}^{2}\right)$ & $33 \cdot 5$ & $5 \cdot 8$ \\
\hline WHR & 0.98 & $2 \cdot 20$ \\
\hline WC $(\mathrm{cm})$ & $101 \cdot 2$ & $14 \cdot 6$ \\
\hline Education (years) & $11 \cdot 3$ & $4 \cdot 0$ \\
\hline \multirow[t]{2}{*}{ Parity } & $2 \cdot 8$ & $2 \cdot 1$ \\
\hline & $n$ & $\%$ \\
\hline \multicolumn{3}{|l|}{ Marital status } \\
\hline Married & 750 & $84 \cdot 5$ \\
\hline Single & 138 & $15 \cdot 5$ \\
\hline
\end{tabular}

WHR, waist:hip ratio; WC, waist circumference. 
Table 2 Comparison of measured variables in three levels of education controlling for age: Iranian women, Sistan and Baluchestan Province

\begin{tabular}{|c|c|c|c|c|c|c|c|}
\hline & \multicolumn{6}{|c|}{ Level of education } & \multirow[b]{3}{*}{$P$} \\
\hline & \multicolumn{2}{|c|}{ Illiterate or low literacy (Group 1) } & \multicolumn{2}{|c|}{ Intermediary \& high school (Group 2) } & \multicolumn{2}{|c|}{ University graduates (Group 3) } & \\
\hline & Mean & SD & Mean & SD & Mean & SD & \\
\hline $\operatorname{BMI}\left(\mathrm{kg} / \mathrm{m}^{2}\right)$ & $35 \cdot 8$ & $5 \cdot 7$ & $33 \cdot 6$ & $5 \cdot 6$ & $31 \cdot 8$ & $5 \cdot 5$ & $\begin{array}{l}<0.05^{\star} \\
<0.05 \\
<0.05\end{array}$ \\
\hline WHR & 0.94 & $0 \cdot 29$ & $0 \cdot 89$ & $0 \cdot 11$ & $1 \cdot 13$ & $3 \cdot 84$ & $\begin{array}{l}\mathrm{NS}^{*} \\
\mathrm{NS}+ \\
\mathrm{NS} \neq\end{array}$ \\
\hline WC $(\mathrm{cm})$ & $106 \cdot 8$ & $15 \cdot 0$ & $101 \cdot 8$ & $14 \cdot 4$ & $96 \cdot 8$ & $13 \cdot 0$ & $\begin{array}{l}<0.05^{\star} \\
<0.05 \\
<0.05\end{array}$ \\
\hline Parity & $4 \cdot 1$ & $2 \cdot 8$ & $2 \cdot 2$ & $1 \cdot 4$ & $1 \cdot 9$ & 0.9 & $\begin{array}{c}<0.05^{\star} \\
<0.05+ \\
\text { NS }\end{array}$ \\
\hline
\end{tabular}

WHR, waist:hip ratio; WC, waist circumference.

${ }^{*}$ Comparison between Group 1 and Group 2.

tComparison between Group 1 and Group 3.

‡Comparison between Group 2 and Group 3.

Table 3 Results of multiple linear regression models (BMI, WHR and WC as dependent variables and age, education and parity as independent variables): Iranian women, Sistan and Baluchestan Province

\begin{tabular}{llcll}
\hline \multicolumn{1}{c}{$R^{2}$} & \multicolumn{1}{c}{$B$} & \multicolumn{1}{c}{ SD } & \multicolumn{1}{c}{$P$} \\
\hline BMI & & & & \\
Age & 0.058 & 0.024 & 0.054 & 0.6 \\
$\quad$ Education (years) & 0.068 & -0.350 & 0.108 & 0.001 \\
Parity & 0.13 & 0.65 & 0.22 & 0.003 \\
$\quad$ Constant & - & 35.13 & 2.11 & 0.0001 \\
WHR & & & & \\
Age & 0.009 & -0.002 & 0.003 & 0.5 \\
Education (years) & 0.001 & -0.006 & 0.006 & 0.32 \\
Parity & 0.029 & 0.025 & 0.014 & 0.08 \\
Constant & - & 24.10 & 1.70 & 0.001 \\
WC & & & & \\
$\quad$ Age & 0.068 & 0.067 & 0.120 & 0.5 \\
Education (years) & 0.08 & -1.08 & 0.25 & 0.001 \\
Parity & 0.12 & 1.23 & 0.51 & 0.01 \\
Constant & - & 31.00 & 1.90 & 0.001 \\
\hline
\end{tabular}

WHR, waist:hip ratio; WC, waist circumference.

(85\%) reported no physical activity, $13 \%$ stated it was less than once a week and $2 \%$ at least once a week. After controlling for age, comparison of measured variables revealed a significant inverse relationship of education level with BMI, WC and parity. There was no significant correlation between educational level and WHR. Therefore women with higher education level had lower BMI, WC and parity (Table 2). Multiple linear regression analyses were conducted separately with BMI, WHR and WC as dependent variables and age, level of education and parity as independent variables. We found a significant negative association of BMI and WC with education level and a significant positive association of BMI and WC with parity. There was no meaningful relationship between WHR and the mentioned variables (Table 3).
Finally, logistic regression model analyses between $\mathrm{BMI}$ and the other variables were performed. The data are presented in Table 4.

\section{Discussion}

The primary objective of the present study was to examine the relationships between SES and BMI, WHR and WC in a group of Iranian women living in Sistan and Baluchestan Province. Our findings suggest that socialeconomic factors play an important role in associations with obesity. We conclude that educational level, marital status and parity have significant associations with BMI and WC in Iranian women.

Much of the trend towards increased body size among women in Sistan and Baluchestan Province has been attributed to the processes of economic modernization and socio-economic change. Some studies have shown that environmental factors can affect people's energy intake and expenditure ${ }^{(21)}$. Women could be most significantly affected by the revolution in food preparation because they have the greatest opportunity to take advantage of the technical changes. These facilities will cause more sedentary lifestyles in women ${ }^{(22)}$.

In the present study there was a powerful inverse relationship between level of education and obesity in women. These correlations were highest in illiterate or low literacy women and lowest in ones who were graduates from universities or colleges. The same finding is supported by other studies ${ }^{(3,23)}$, although there are some contrasting data on this issue ${ }^{(24,25)}$. In Iran, women of high educational level have more employment than those with less education, which could explain the increased effect of educational level on obesity. A relationship 
Table 4 Results of logistic regression models (dependent variable is obesity: $\mathrm{BMI}<30 \mathrm{~kg} / \mathrm{m}^{2}=0, \mathrm{BMI} \geq 30 \mathrm{~kg} / \mathrm{m}^{2}=1$ ): Iranian women, Sistan and Baluchestan Province

\begin{tabular}{|c|c|c|c|c|c|}
\hline Parameter & $B$ & OR & $95 \% \mathrm{Cl}$ & SD & $P$ \\
\hline \multicolumn{6}{|l|}{ Level of education } \\
\hline University graduates & & $1 \cdot 00$ & & & \\
\hline Intermediary \& high school & $1 \cdot 43$ & $4 \cdot 20$ & $1 \cdot 64,10 \cdot 83$ & 0.48 & 0.003 \\
\hline Illiterate or low literacy & $1 \cdot 30$ & $3 \cdot 70$ & $1 \cdot 31,10 \cdot 50$ & 0.53 & 0.013 \\
\hline \multicolumn{6}{|l|}{ Marital status } \\
\hline Married & & $1 \cdot 00$ & & & \\
\hline Single & $-1 \cdot 90$ & $0 \cdot 15$ & $0 \cdot 02,1 \cdot 20$ & $1 \cdot 08$ & 0.05 \\
\hline \multicolumn{6}{|l|}{ Physical activity } \\
\hline Yes & & $1 \cdot 00$ & & & \\
\hline No & $0 \cdot 18$ & $1 \cdot 20$ & $0 \cdot 13,11 \cdot 60$ & $1 \cdot 13$ & 0.8 \\
\hline \multicolumn{6}{|l|}{ Parity } \\
\hline$>5$ & & 1.00 & & & \\
\hline $2-5$ & $-1 \cdot 02$ & 0.36 & $0 \cdot 02,2 \cdot 40$ & $1 \cdot 11$ & 0.24 \\
\hline$<2$ & $1 \cdot 07$ & 0.34 & $0.04,3 \cdot 30$ & $1 \cdot 11$ & 0.03 \\
\hline \multicolumn{6}{|l|}{ WC } \\
\hline$<88 \mathrm{~cm}$ & & $1 \cdot 00$ & & & \\
\hline$\geq 88 \mathrm{~cm}$ & $2 \cdot 40$ & $11 \cdot 20$ & $3.00,41 \cdot 05$ & 0.66 & 0.001 \\
\hline \multicolumn{6}{|l|}{ WHR } \\
\hline$<0.85$ & & $1 \cdot 00$ & & & \\
\hline$\geq 0.85$ & $-0 \cdot 60$ & 0.54 & $0 \cdot 21,1 \cdot 44$ & 0.48 & 0.21 \\
\hline Constant & -0.58 & - & - & $1 \cdot 70$ & 0.7 \\
\hline
\end{tabular}

WHR, waist:ratio; WC, waist circumference.

between BMI and unemployment has also been shown to exist in women ${ }^{(26)}$. However, the greater frequency of perceived overweight in women with high educational level could lead them to go on weight-reducing diets or take other measures to lose weight in larger proportions than women with an elementary level of education ${ }^{(27,28)}$. It should also be noted that more highly qualified women have greater access to weight-reducing treatments as these carry a certain cost. Since our analysis is based on crosssectional data, further studies are needed to clarify it.

We also observed remarkable differences in parity and obesity among women in the present study. Reproduction is considered an important determinant of weight gain during a woman's life. This factor has been related with the social gradient in obesity in women because weight gained during pregnancy is not lost completely at term $^{(29)}$. Some research shows that women with lower age and social level have more children ${ }^{(30)}$. This fact may be important in explaining the social differences in obesity among women. BMI has been shown to increase with the number of pregnancies ${ }^{(31)}$. Our data revealed similar findings.

Moreover, physical activity is reported as a determinant of body weight in some studies ${ }^{(32)}$. Regular physical activity helps reduce the risk of heart disease ${ }^{(33,34)}$, control mild hypertension ${ }^{(35)}$, modify blood lipids ${ }^{(36,37)}$ and protect against the onset of osteoporosis in women ${ }^{(38)}$. One of the most striking characteristics of our study was the low level of physical activity reported by most of the participants. In this region of Iran, women do not have much access to sporting activities, and physical activity is restricted to housework. Traditionally, some of them consider obesity to be a sign of good health and beauty, an attitude that may contribute to the current situation.
Marital status represents another social dimension. The present study showed that married women gain more weight than single women. In Iran, marriage usually changes women's attitude to life. They prefer to spend more time with their family and less think about their own body shape. However, intensive investigation is needed in Iran to conclude better results.

\section{Conclusions}

The present study revealed that lack of exercise, multiple pregnancies, marital status and education are some of the possible explanations for obesity among women residing in Sistan and Baluchestan Province. Obesity prevention should be a relevant topic on the public health agenda in developing countries such as Iran. Without developing effective strategies to modify the current situation, it is likely that the obesity epidemic will continue in the future.

\section{Acknowledgements}

Conflicts of interest: There is no conflict of interest.

Source of funding: The Medical Faculty of Zahedan University of Medical Sciences funded the research.

Author contributions: M.S. was project manager and designer of the research; T.S. collaborated in writing the paper and collecting data; H.A. collaborated in analysing the data.

Acknowledgement: Our thanks go to all who participated actively in this project. We are thankful to the Research Center for Children and Adolescents Health for their invaluable help. 


\section{References}

1. Metcalf P, Scragg R \& Davis P (2007) Relationship of different measures of socioeconomic status with cardiovascular disease risk factors and lifestyle in a New Zealand workforce survey. N Z Med J 120, U2392.

2. Yu Z, Nissinen A, Vartiainen E, Hu G, Tian H \& Guo Z (2002) Socio-economic status and serum lipids: a crosssectional study in a Chinese urban population. J Clin Epidemiol 55, 143-149.

3. Dastgiri S, Mahdavi R, TuTunchi H \& Faramarzi E (2006) Prevalence of obesity, food choices and socio-economic status: a cross-sectional study in the north-west of Iran. Public Health Nutr 9, 996-1000.

4. Sobal J (1991) Obesity and socioeconomic status: a framework for examining relationships between physical and social variables. Med Anthropol 13, 231-247.

5. Mokdad AH, Serdula MK, Dietz WH, Bowman BA, Marks JS \& Koplan JP (1999) The spread of the obesity epidemic in the United States, 1991-1998. JAMA 282, 1519-1522.

6. Sobal J \& Stunkard AJ (1989) Socioeconomic status and obesity: a review of the literature. Psychol Bull 105, 260-275.

7. Wang Y, Monteiro C \& Popkin BM (2002) Trends of obesity and underweight in older children and adolescents in the United States, Brazil, China, and Russia. Am J Clin Nutr $\mathbf{7 5}$, 971-977.

8. Popkin BM, Conde W, Hou N \& Monteiro C (2006) Is there a lag globally in overweight trends for children compared with adults? Obesity (Silver Spring) 14, 1846-1853.

9. Wolf WS, Sobal J, Olson CM, Frongillo EA Jr \& Williamson DF (1997) Parity-associated weight gain and its modification by sociodemographic and behavioral factors: a prospective analysis in US women. Int J Obes Relat Metab Disord 21, 802-810.

10. Lee SK, Sobal J, Frongillo EA, Olson CM \& Wolfe WS (2005) Parity and body weight in the United States: differences by race and size of place of residence. Obes Res 13, 1263-1269.

11. Kim SA, Stein AD \& Martorell R (2007) Country development and the association between parity and overweight. Int J Obes (Lond) 31, 805-812.

12. Azizi F, Allahverdian S, Mirmiran P, Rahmani M \& Mohammadi F (2001) Dietary factors and body mass index in a group of Iranian adolescents: Tehran Lipid and Glucose Study - 2. Int J Vitam Nutr Res 71, 123-127.

13. Pishdad GR (1996) Overweight and obesity in adults aged 20-74 in southern Iran. Int J Obes Relat Metab Disord 20, 963-965.

14. Azadbakht L, Mirmiran P, Shiva N \& Azizi F (2005) General obesity and central adiposity in a representative sample of Tehranian adults: prevalence and determinants. Int J Vitam Nutr Res 75, 297-304.

15. Rashidi A, Mohammadpour-Ahranjani B, Vafa MR \& Karandish M (2005) Prevalence of obesity in Iran. Obes $\operatorname{Rev}$ 6, 191-192.

16. Jamshidbygi A (2002) Iran vital statistics and its outcomes in 2001. Iranian Behvarz Journal 54, 15-16.

17. World Health Organization (1997) The World Health Report 1997. Obesity: Preventing and Managing the Global Epidemic. Geneva: WHO.

18. Yu Z, Nissinen A, Vartiainen E, Song G, Guo Z \& Tian H (2000) Changes in cardiovascular risk factors in different socioeconomic groups: seven year trends in a Chinese urban population. J Epidemiol Community Health 54, 692-696.
19. Osler M, Gerdes LU, Davidsen M, Bronnum-Hansen H, Madsen M, Jørgensen T \& Schroll M (2000) Socioeconomic status and trends in risk factors for cardiovascular diseases in the Danish MONICA population, 1982-1992. J Epidemiol Community Health 54, 108-113.

20. Schröder H, Rohlfs I, Schmelz EM \& Marrugat J (2004) Relationship of socioeconomic status with cardiovascular risk factors and lifestyle in a Mediterranean population. Eur J Nutr 43, 77-85.

21. Hill JO, Wyatt HR, Reed GW \& Peters JC (2003) Obesity and the environment: where do we go from here? Science 299, 853-855.

22. Gates D, Brehm B, Hutton S, Singler M \& Poeppelman A (2006) Changing the work environment to promote wellness: a focus group study. AAOHN J 54, 515-520.

23. Moreira P \& Padrao P (2006) Educational, economic and dietary determinants of obesity in Portuguese adults: a cross-sectional study. Eat Behav 7, 220-228.

24. Du S, Lu B, Zhai F \& Popkin BM (2002) A new stage of the nutrition transition in China. Public Health Nutr 5, 169-174.

25. Al-Nuaim AA, Bamgboye EA, al-Rubeaan KA \& al-Mazrou Y (1997) Overweight and obesity in Saudi Arabian adult population, role of socio-demographic variables. $\mathrm{J}$ Community Health 22, 211-223.

26. Sarlio-Lähteenkorva S \& Lahelma E (1999) The association of body mass index with social and economic disadvantage in women and men. Int J Epidemiol 28, 445-449.

27. Levy AS \& Heaton AW (1993) Weight control practices of US adults trying to lose weight. Ann Intern Med 119, 661-666.

28. Serdula MK, Collins ME, Willianson DF, Anda RF, Pamuk E \& Byers TE (1993) Weight control practices of US adolescents and adults. Ann Intern Med 119, 667-671.

29. Noppa H \& Bengtsson C (1980) Obesity in relation to socioeconomic status.A population study of women in Göteborg, Sweden. J Epidemiol Community Health 34, 139-142.

30. Wamala SP, Wolk A \& Orth-Gomér K (1997) Determinants of obesity in relation to socioeconomic status among middle-aged Swedish women. Prev Med 26, 734-744.

31. Rissanen AM, Heliovaara M, Knekt P, Reunanen A \& Aromaa A (1991) Determinants of weight gain and overweight in adult Finns. Eur J Clin Nutr 45, 419-430.

32. Croff JB, Strogatz DS, James SA, Keenan NL, Ammerman AS, Mararcher AM \& Haines PS (1992) Socioeconomic and behavioral correlates of body mass index in black adults: The Pitt County Study. Am J Public Health 82, 821-826.

33. Fransson E, de Faire U, Ahlbom A, Reuterwall C, Hallqvist J \& Alfredsson L (2006) The effect of leisure-time physical activity on the risk of acute myocardial infarction depending on body mass index: a population-based case-control study. BMC Public Health 6, 296.

34. Corrado D, Migliore F, Basso C \& Thiene G (2006) Exercise and the risk of sudden cardiac death. Herz 31, 553-558.

35. Hayashi T, Ohshige $\mathrm{K} \&$ Tochikubo O (2007) Exclusion of influence of physical activity on ambulatory blood pressure. Clin Exp Hypertens 29, 23-30.

36. Mbalilaki JA, Hellenius ML, Masesa Z, Hostmark AT, Sundquist J \& Stromme SB (2007) Physical activity and blood lipids in rural and urban Tanzanians. Nutr Metab Cardiovasc Dis 17, 344-348.

37. Adamu B, Sani MU \& Abdu A (2006) Physical exercise and health: a review. Niger J Med 15, 190-196.

38. Jamsa T, Vainionpaa A, Korpelainen R, Vihriala E \& Leppaluoto J (2006) Effect of daily physical activity on proximal femur. Clin Biomech (Bristol, Avon) 21, 1-7. 